\title{
Evaluation of the Relationship between Serum Ferritin Level and Renal Function in Patients with Thalassemia Major
}

Alireza Eskandarifar' ${ }^{1}$, Borhan Moradveisi ${ }^{2}$, Daem Roshani ${ }^{3}$, Yasin Padash $^{4}$

1.Assistant professor, Department of Pediatric, Faculty of Medicine, Kurdistan University of Medical Sciences, Sanandaj, Iran., (Corresponding author)Email: are1345@yahoo.com, Tel: 087 33285910, ORCID ID: 0000-0001-9173-359X.

2. Assistant professor, Department of Pediatric, Faculty of Medicine, Kurdistan University of Medical Sciences, Sanandaj, Iran, ORCID ID: 0000-0002-1952-4344.

3. Associated professor, Department of Epidemiology and Biostatistics, School of Medicine, Kurdistan University of Medical Sciences, Sanandaj, Iran, ORCID ID: 0000-0003-4746-1114.

4.Medial Student, Student Research Committee, Kurdistan University of Medical Sciences, Sanandaj, Iran. ORCID ID:00000002-4824-2696.

\begin{abstract}
Background and Aim: Serum ferritin in patients with thalassemia major is an indicator of iron overload, which is the main cause of damage to various organs of the body in patients with thalassemia major. The aim of this study was to investigate the relationship between serum ferritin level and renal function in thalassemia major patients.

Materials and Methods: This descriptive and cross-sectional study was performed on patients with thalassemia major in Kurdistan province (west region of Iran) in 2019. All patients with thalassemia major were evaluated in terms of having regular blood transfusions for at least 1 year. The obtained data were entered into SPSS 22 software and statistically analyzed after measuring serum ferritin, creatinine and calculating glomerular filtration rate (GFR).

Results: In this study, 122 patients were evaluated according to the inclusion and exclusion criteria. $54.1 \%$ were male and $45.9 \%$ were female. The mean age of patients was $20.28 \pm 8.14$ years, the mean hemoglobin was $8.95 \pm 1.17 \mathrm{gr} / \mathrm{dl}$, the mean ferritin was $2812 \pm 2134 \mathrm{ng} / \mathrm{ml}$, the mean creatinine was $0.65 \pm 0.17 \mathrm{mg} / \mathrm{dl}$ and the mean GFR $(\mathrm{ml} / \mathrm{min})$ was $122.19 \pm 24.13$. No significant correlation was found between GFR and serum ferritin $(\mathrm{P}>0.05)$.

Conclusion: Due to the lack of correlation between serum ferritin and GFR, it can be concluded that iron overload has no role in possible glomerular damage in thalassemia major patients.
\end{abstract}

Keywords: Thalassemia Major, Ferritin, Glomerular Filtration Rate, Renal Function

Received: Oct 20, 2020

Accepted: Dec 19, 2020

How to cite the article: Alireza Eskandarifar, Borhan Moradveisi, Daem Roshani, Yasin Padash. Evaluation of the Relationship Between Serum Ferritin Level and Renal Function in Patients with Thalassemia Major.SJKU 2021;26(1):33-39.

Copyright (C) 2018 the Author (s). Published by Kurdistan University of Medical Sciences. This is an open access article distributed under the terms of the Creative Commons Attribution-Non Commercial License 4.0 (CCBYNC), where it is permissible to download, share, remix, transform, and buildup the work provided it is properly cited. The work cannot be used commercially without permission from the journal 


\title{
بررسى ارتباط بين ميزان فريتين سرم و عملكرد كليوى در بيماران تالاسمى مازور
}

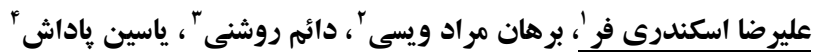

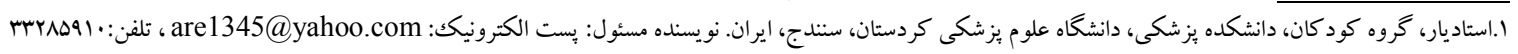

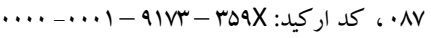

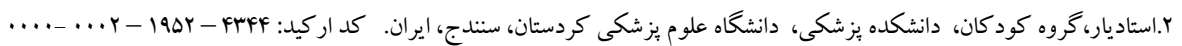

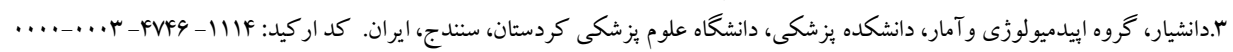

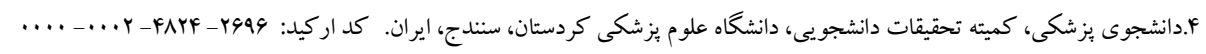

جكيده

زمينه و هدف: فريتين سرم در بيماران تالاسمى مازور شاخصى از ميزان بار آهن است. در بيماران تالاسمى مازور اضافه بار آهن

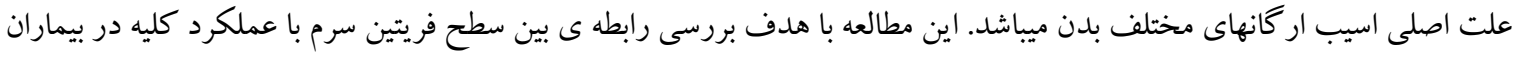
تالاسمى انجام شده است. مواد و روشها: اين مطالعه توصيفى تحليلى و مقطعى بر روى بيماران مبتلا به تالاسمى مازور استان كردستان (واقع در غرب ايران)

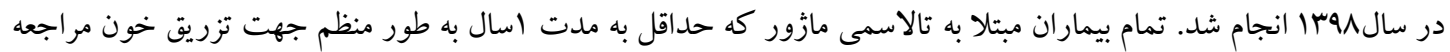

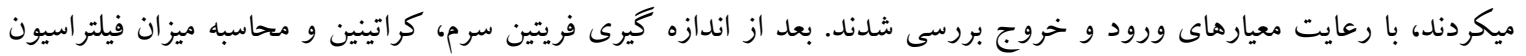

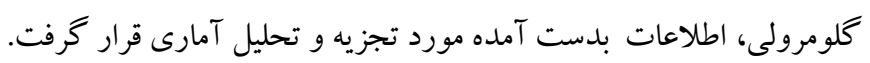

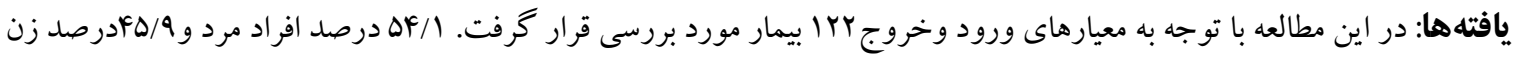

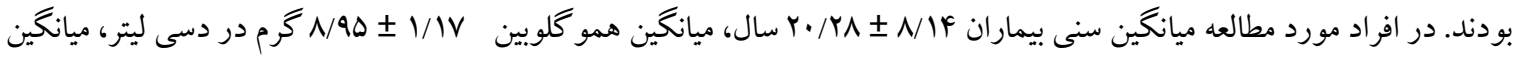

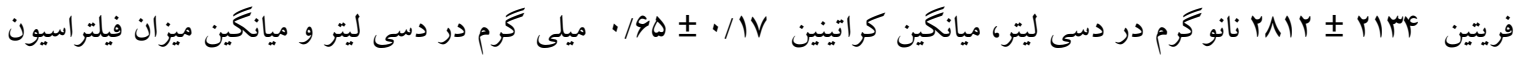

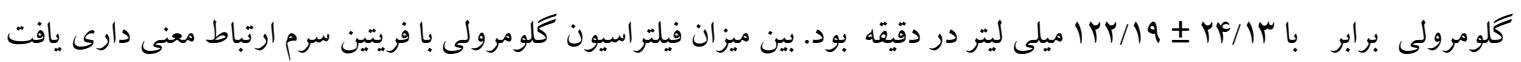

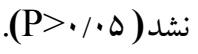
نتيجه كيرى: با توجه به عدم ارتباط بين ميزان فريتين سرم با ميزان فيلتراسيون گلومرولى مى توان گفت كه اضافه بار آهن در اسيب

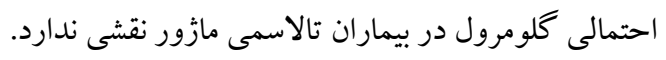

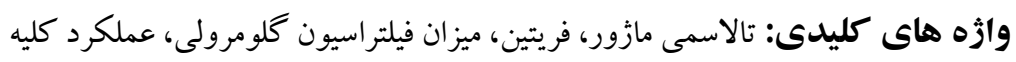

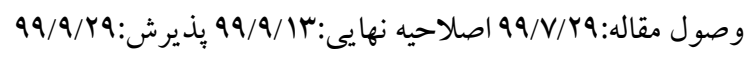




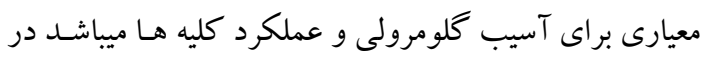
اين مطالعه سعى شده است تا ارتباط بين فريتين سرم (بعنوان

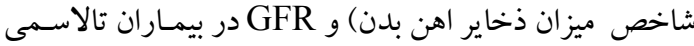
مازور بررسى و نقش ذخاير بـالاى آهن در عملكرد كليوى

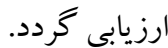

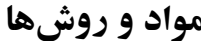

اين مطالعه از نوع توصيفى - تحليلى و مقطعى بـوده كه در

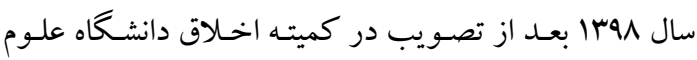

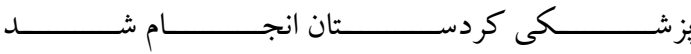

.(IR.MUK.REC.1398.173)

نمونه گيرى بصورت سر شمارى و شامل تمامى بيماران مبتلا به تالاسـمى مـازور بـود كـه حـداقل يكسـال جهـت دريافت

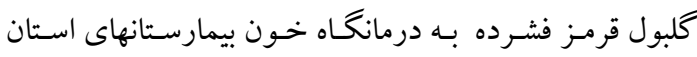
كردستان واقع در غرب ايران مر اجعه مى كردند. جهت كاهش عوامل مخدوش كننده موثر بر عملكرد كليه ها، افرادى كه داراى بيمارى زمينه اى كليوى، فشار خون بالا،

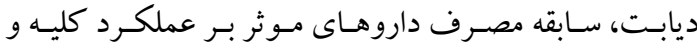
آزمايش ادرار غير طبيعى (هماجورى، ييورى، بروتينورى) و

سونو كرافى غيرطبيعى كليه بودند، از مطالعه حذف شدند.

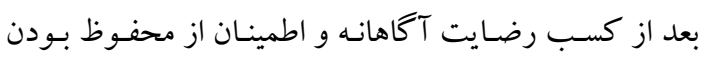

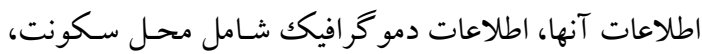
سن، جنس، وزن، قد، كراتينين سرم، GFR و فريتين سرم در فرد يرسشنامه اي كه طراحى شده بود ثبت گرديد،

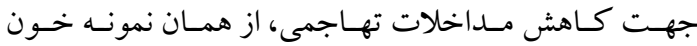
وريدى كه جهت انجام آزمايشات روتين قبل از تزريق خون كرفته مى شد، استفاده گرديد. ه ميلى ليتر خون هيارينه را به آزمايشكاه منتقل كرده و سطح سئح سرمى فريتين به روش الكترو كمى لومينسانس و بـا استفاده از

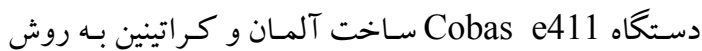

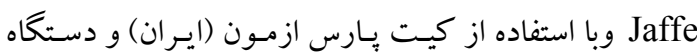

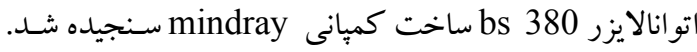
جهت محاسبه GFR در بيمـاران كمتر از ماسـال از فرمول
بتا تالاسمى از علل شايع كمى خـونى (آنمسى) بـه خصـوص در قسمت هايى از جهان مانند ناحيه ى مديترانه اي، خاورميانه و

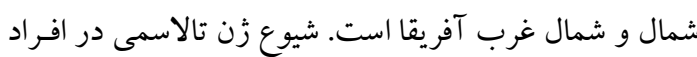

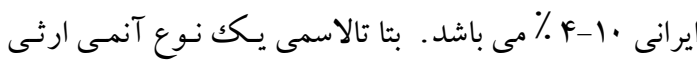

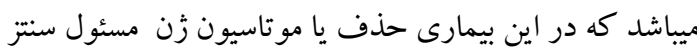

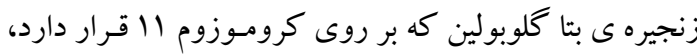

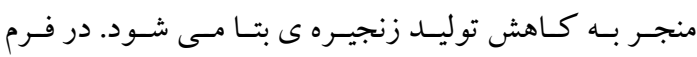

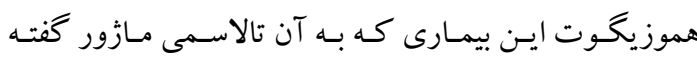

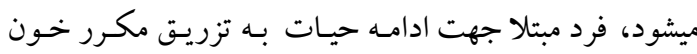

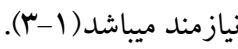
با دريافت يكك سى سى كلبول قرمز فشرده blood cell) افزايش مىيابد در نتيجه جهت كاهش بار آهن اضافى،

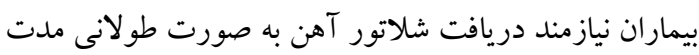

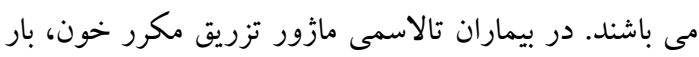

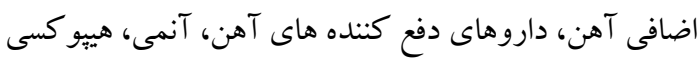

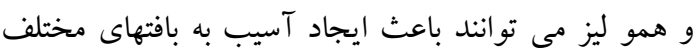

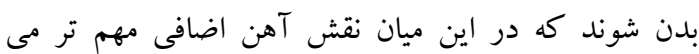

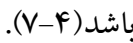
در اين بيماران اغلب اختلال عملكرد شديدى در سيستم قلبى ريوى و سيستم رتيكولواندوتليال ديده ميشود اما دركيرى هاى كليوى كمتر بروز ميكند(A-V). بيمارى مزمن كليه (Chronic kidney disease, CKD) با آسيب دائمى كليه و كاهش تدريجى عملكرد كليه مشخص مى شود. مراحل CKD و ميزان كاهش عملكرد

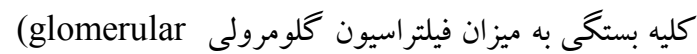
filtration rate, GFR) علامت بالينى بوده و به تدريج با كاهش GFR ظاهر

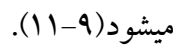
مطالعات قبلى در بيماران تالاسمى مازور عموما بـر اختلالات

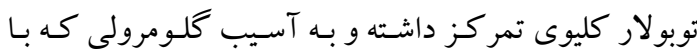
كاهش GFR مشـخص ميشود، كمتـر توجه شـــه اسـت. از

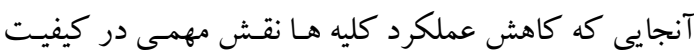


براسى ارتباط بين ميزان...

با توجه به معيارهـاى ورود و خـروج مجموعـا ب ا نفـر مـورد

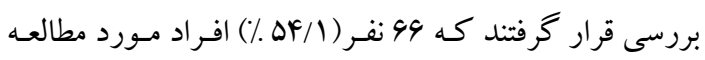

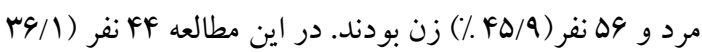

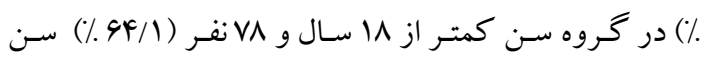
بيشتر يا مساوى \ل سال داشتند(جدول ا ). در اين مطالعه ميانگين سنى بيماران N/IF

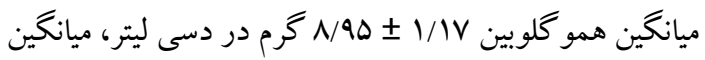

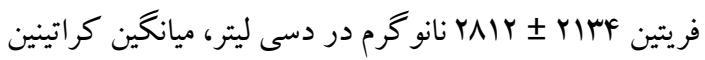

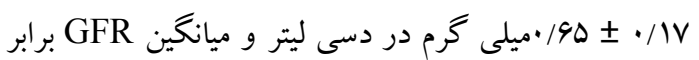

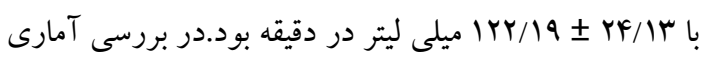
به روش بيرسون بين GFR با فريتين ارتباط معنى دارى

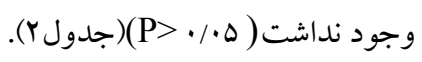

جدول ا. توزيع فراوانى افراد مورد مطالعه از نظر سن و جنس ورد لـ

\begin{tabular}{|c|c|c|c|}
\hline درصد & فراوانى & & متغيير \\
\hline$\Delta F / I$ & 94 & مرد & جنسيت \\
\hline$F \Delta / 9$ & $\Delta \varphi$ & زن & \\
\hline$r 9 / 1$ & $F F$ & كمتر از ^1 سال & سن \\
\hline $9 \pi / 9$ & $\mathrm{v \Lambda}$ & بيشتر يا مساوى 11 & \\
\hline
\end{tabular}

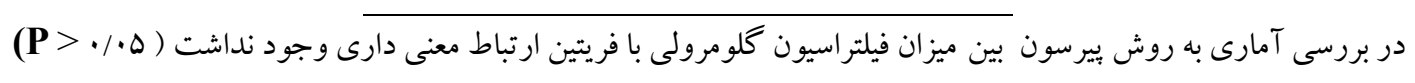
جدول r.ميانكين و انحراف معيار متغيير هاى كمى مورد بررسى برئ

\begin{tabular}{|c|c|c|c|}
\hline $\mathbf{P}$ & انحراف معيار & ميانكين & متغيير \\
\hline- & $\Lambda / I F$ & $r \cdot / r \Lambda$ & سن \\
\hline- & $1 D / Y F$ & $109 / \mu$. & قدانتيمتر ) \\
\hline- & Ir/VA & $\$ 9 / \cdot 1$ & 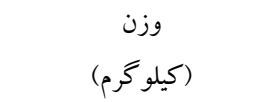 \\
\hline- & $\cdot / 1 \mathrm{~V}$ & .190 & 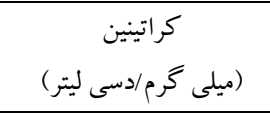 \\
\hline- & $1 / 1 \mathrm{~V}$ & $\Lambda / ৭ \Delta$ & 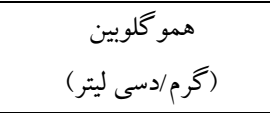 \\
\hline \multirow[t]{2}{*}{$>\cdot / \cdot \Delta$} & rimf & YNIT & 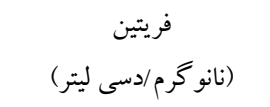 \\
\hline & $r F / I T$ & $1 Y r / 19$ & ميز ان فيلتراسيون كُلومرولى (ميلى ليتر /دقيقه) \\
\hline
\end{tabular}


بيماران مبتلا به تالاسمى مازور بعلت آنمى شديد جهت ادامـهـ

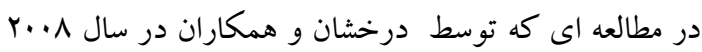
حيات اغلب نيازمند به دريافت مكرر خـون ميباشـند. از آنجا

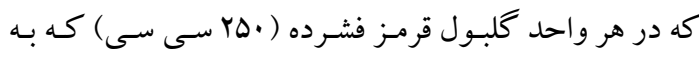
در بيمارستان نمازى شيراز انجام شد، 1+1 بيمار مبتلا به

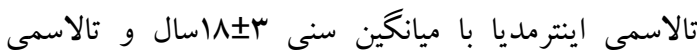

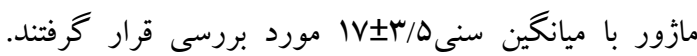

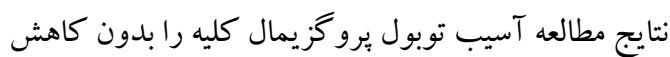

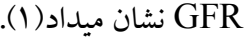

در مقابل در مطالعه ديخرى ارتباط معكوس بين ميزان GFR

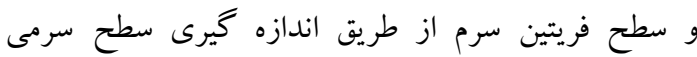
سيستاتين _ سى (Cystatin-C) مشاهده شده است(YQT). اين اختلاف بين نتايج دو مطالعه مى تواند ناشى از تفاوت در روش اندازه گيرى GFR باشد. در مطالعه اى كه ملكى در سال II ب در بيمارستان كود كان تبريز با هدف بررسى عملكرد گلومرولى انجام داد، بهو بيمار

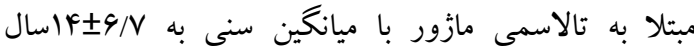

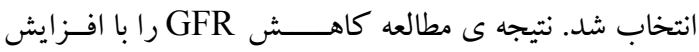

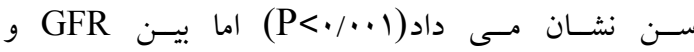
فــــيتين رابطه ى معنا دارى مشاهده نشد(If).

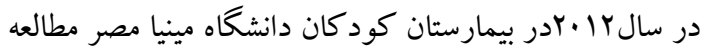
اى با هدف بررسى شيوع اختلال كلومرولار در بيماران مبتلا به تالاسمى مازور انجام شد كه نتيجه ى مطالعه آسيب كلومرولار و كاهش GFR را در بيماران تالاسمى مازور

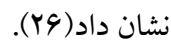
در مطالعه نيكاور در سال Y.IV جنين نتيجه گيرى شد كه عملكرد توبولى و گلومرولى كليه ها در انواع مختلف بيماران

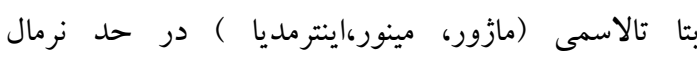

$$
\text { ميباشد(YV). }
$$

در مطالعه ما نيز ارتباط معنى دارى بين فريتين و GFR ديده

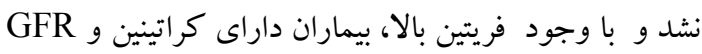
نرمال بودند و عملكرد كليه آنها در حد نرمال حفظ شده بود.

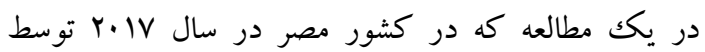

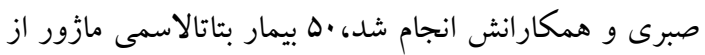

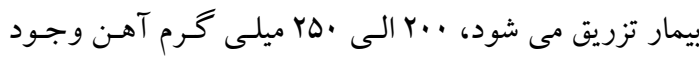

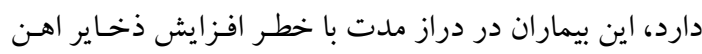

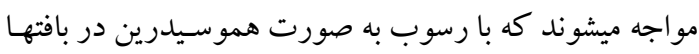

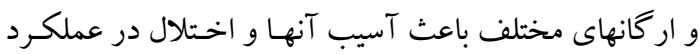

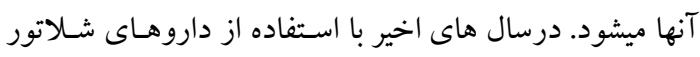

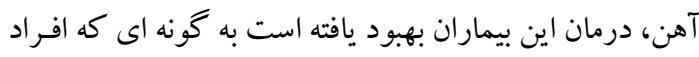

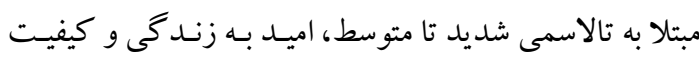

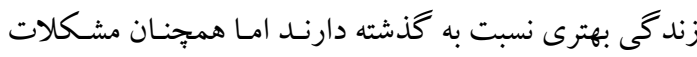

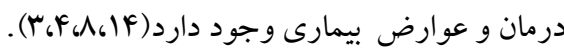

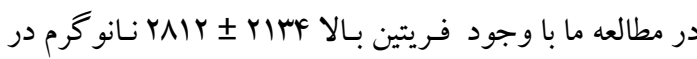

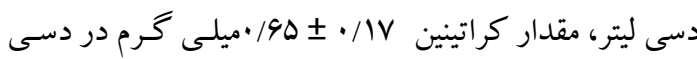

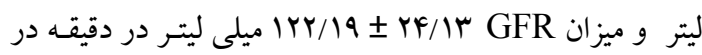

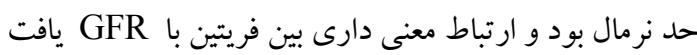

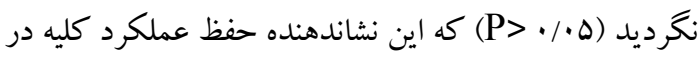

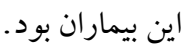

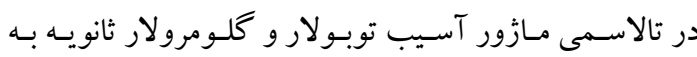
كـاهش توليـد آدنـوزين تـرى فسـفات، اسـترس اكسيداتيو،

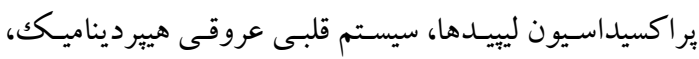

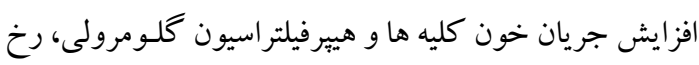
ميدهـــ. دراغلـب مطالعـات كذشـته آسـيب توبــولار كليـهـ بصـورت يروتئينـورى، آمينواسـيدورى، اسـمولاليته ى بـايين

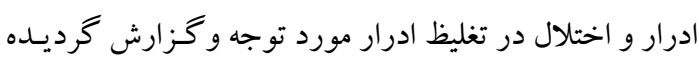

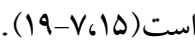

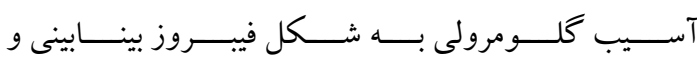

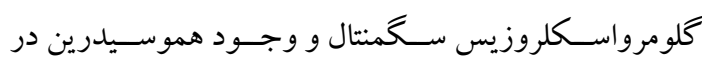
اتويسى برخى بيماران ثابت شده اسـت. ايسن تغييـرات ممكـن

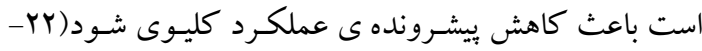

فريتين يكك بروتئين فاز حاد است و به عنوان معيار ذخاير آهن بدن نيز مورد استفاده قرار ميخيرد در آسيب توبولار يروتئ 


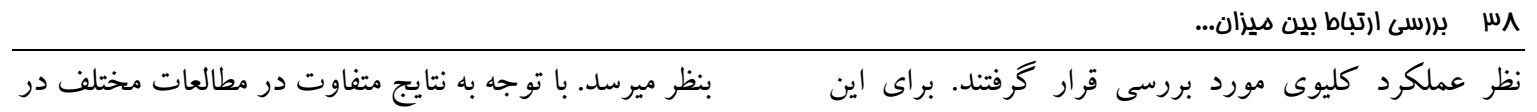

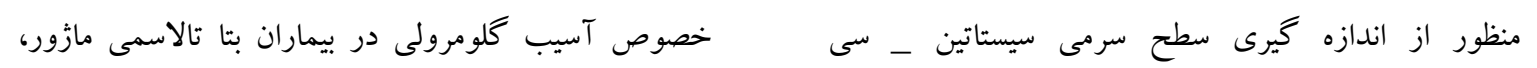

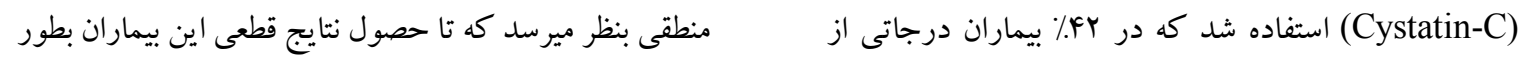

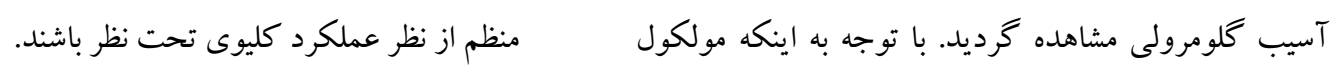

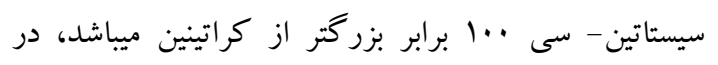

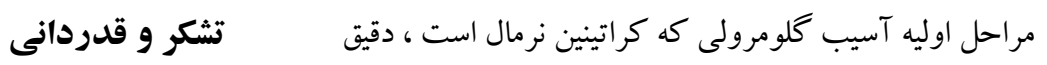

$$
\begin{aligned}
& \text { نويسند كان مقاله از دانشگاه علوم يز شكى كردستان جهان } \\
& \text { تأييد و تصويب اين طرح تشكر و قدردانى مينمايند. } \\
& \text { تر و سريعتر مى تواند كاهش عملكرد كلومرول را نشان } \\
& \text { دهد (YN). }
\end{aligned}
$$

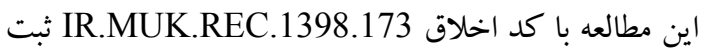

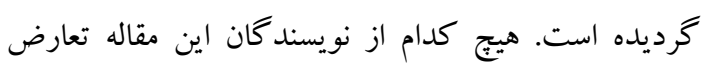

$$
\begin{aligned}
& \text { منافعى براى انتشار آن ندارند. }
\end{aligned}
$$

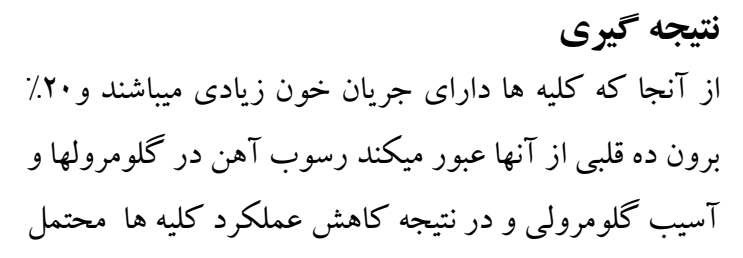

منابc

1. Derakhshan A, Karimi M, Moghaddam AG. Comparative Evaluation of Renal Findings in BetaThalassemia Major and Intermedia. Saudi J Kidney Dis Transept. 2008; 19: 206-209.

2. Muncie HL, J R, Campbell JS. Alpha and beta thalassemia. Am Fam Physician. 2009; 80(4): 339344.

3. Koliakos G, Popachristous F, Koussi A, Perifanis V, Tsatrra I, Souliou E, et al. Urine Biochemical Markers of early Renal Dysfunction are Associated with Iron Overload in Beta Thalassemia. Clin Lab Haematol. 2003; 25: 105-109.

4. Tantawy AA, El Bablawy N, Adly AA, Ebeid FS. Early Predictors of Renal Dysfunction in Egyptian Patients with $\beta$-thalassemia Major and intermedia. Mediterr J Hematol Infect Dis. 2014;6: e201405.

5. Mallat N, Mallat S, Musallam K, Taher A. Potential Mechanisms for Renal Damage in betaThalassemia. JNEPHROL. 2013; 26(5): 821-828.

6. Musallam KM, Taher AT. Mechanisms of renal disease in $\beta$-thalassemia. J Am Soc Nephrol. 2012; 23: $1299-1302$.

7. Sumboonnanonda A, Malasit P, Tanphaichitr VS, Ong-Ajyooth S, Petrarat S, Vongjirad A. Renal Tubular Dysfunction in Thalassemia. Pediatr Nephrol. 2003; 18 (3): 257-260.

8. Borgna-Pignatti C, Gamberini MR. Complications of Thalassemia Major and Their Treatment. Expert RevHematol. 2011; 4: 353-366.

9.Mohammed S, Mirza Sharif A, Hemalatha, Shantha K. Thyroid Dysfunctions in Patients with Chronic Renal Failure. Int J Biol Med Res. 2014; 5(1): 3911-3914.

10. Khajehdehi P, Malekmakan L, Pakfetrat M, Roozbeh J, Sayadi M. Prevalence of Chronic Kidney Disease and Its Contributing Risk Factors in Southern Iran: a Cross-sectional Adult Population-based Study. Iran J Kidney Dis. 2014; 8: 2: 109-115.

11. Levey AS, Coresh J, Bolton K, Culleton B, Harvey KS, Ikizler TA, et al. National Kidney Foundation. K/DOQI Clinical Practice Guidelines for Chronic Kidney Disease: Evaluation, Classification and Stratification. Am J Kidney Dis. 2002;39(2):S1-266.

12. Helou R. Should We Continue to Use the Cockcroft-Gault Formula?. Nephron Clin Pract. 2010; 116: $172-186$.

13. Stark E M, Burckart G J. Glomerular Filtration Rate Estimation Formulas for Pediatric and Neonatal Use. J Pediatr Pharmacol Ther. 2018; 23(6): 424-431. 
14. Malaki M, Sorkhabi RS, Shoaran M, Bagheri S, Beta Thalassemia Major: The Effect of Age on Glomerular Filtration Rate. Saudi J Kidney Dis Transpl. 2011; 22(5): 963-968.

15. Bhandari S, Galanello R. Renal Aspects of Thalassaemia a Changing Paradigm. Eur J Haematol. 2012; 89: 187-197.

16. Quinn CT, Johnson VL, Hae-Young Kim, Trachtenberg F, Vogiatzi MG, Kwiatkowski JL, et al. Renal Dysfunction in Patients with Thalassaemia. British Journal of Haematology. 2011; 153: 111-117.

17. Mohkam M, Shamsian BS, Gharib A, Nariman S, Arzanian MT. Early Markers of Renal betaThalassemia Major. pediatr Nephrol. 2008; 23(6): 971-976.

18. Lai ME, Spiga A, Vacquer S, Carta MP, Corrias C, Ponticelli C. Renal Function in Patients with $\beta$ Thalassaemia Major: a long-term follow-up study. Nephrol Dial Transplant. 2012; 27: 3547-3551.

19. Koliakos G, Papachristou F, Koussi A, Perifanis V, Tsatra I, Souliou E, et al. Urine Biochemical Markers of Early Renal Dysfunction in beta Thalassemia. Clin Lab Heamatal. 2003; 25(2); 105-109.

20. Benjamin H, Lavding MD. Renal Lesion And Clinical Anemia With Hemosidrosis. PediatrPathol. 1998; 9: 470-500.

21. Landing BH, Gonick HC, Nadorra RL, Hyman CB, Wells TR, Villarreal-Engelhardt G, et al. Renal Lesions And Clinical Findings in Thalassemia Major and Other Chronic Anemias with Hemosiderosis. PediatrPathol. 1989;9: 479-500 .

22. Smolkin V, Halevy R, Levin C, Mines M, Sakran W, Ilia K, et al. Renal Function in Children with beta-Thalassemia Major and Thalassemia Intermedia. PediatrNephrol. 2008; 23: 1847-1851.

23. Michelakakis H, Dimitriou E, Georgakis H, Premetis E, Karagiorga-Lagana M. Iron Overload and Urinary Lysosomal Enzyme Levels in beta-Thalassemia Major. Eur J Pediatr.1997; 156: 602-604.

24. Sadeghi-Bojd S, Hashemi M, Karimi M. Renal Tubular Function in Patients with beta Thalassemia Major in Zahedan, Southeast Iran. Singapore Med J. 2008; 49(5): 410-412.

25. Papassotiriou I, Margeli A, Hantzi E, Delaporta P, Sergounioti A, Goussetis E, et al. Cystatin C Levels in Patients with beta-Thalassemia During Deferasirox Treatment. Blood Cells Mol Di. 2010; 44: $152-155$.

26. Ali BA, Mahmoud AM. Frequency of Glomerular Dysfunction in Children with Beta Thalassemia Major. Sultan Qaboos University Med J. 2014; 14(1): 88-94.

27. Nickavar A, Qmarsi A, Ansari S, Zarei E. Kidney Function in Patients with Different Variants of Beta-thalassemia. IJKD. 2017; 11: 132-137.

28. Sabry A S, Mohamed A A E H, Alaa E A E H, Seham A K, Hesham G A, Essam A A E, et al. Glomerular Dysfunction in Adult Patients with $\beta$-Thalassemia Major. Open Acc Blood Res Transfus J. 2017; 1(3): 555-564. 